\title{
Multi-objective optimization of magnetic abrasive finishing by desirability function with genetic algorithm
}

\author{
Rajneesh Kumar Singh ${ }^{1}$, Swati Gangwar², D.K. Singh², Shadab Ahmad ${ }^{3}$ \\ ${ }^{1 *}$ Department of Mechanical Engineering, Meerut Institute of Engineering and Technology, Meerut, INDIA \\ ${ }^{2}$ Department of Mechanical Engineering, Madan Mohan Malaviya University of Technology, Gorakhpur, INDIA \\ ${ }^{3}$ Mechanical Engineering Department, Delhi Technological University, New Delhi, India \\ ${ }^{*}$ Corresponding Author: e-mail: rajneeshsingh_rsme@mmmut.ac.in, Tel +91-9918985312 \\ ORCID iDs: https://orcid.org/0000-0002-5823-0939(rajneesh), https://orcid.org/0000-0001-9792-0409(swati)
}

\begin{abstract}
Thermal stability and Surface hardness of the super-finished surface is a very important aspect to preserve the surface texture of workpiece in the MAF process. In this present study, the multi-objective optimization of EN-31 finished through the MAF process. "Increase in Temperature" and "Increase in Hardness" are considered for optimization to diminish their impact on the super-finished surface of EN-31. In present work Desirability function analysis (DFA) has been used to optimize the desired responses of the MAF process. Experiments were designed according to Taguchi L9 orthogonal array for the finishing of EN-31. The experiment results are processed using DFA and Desirability fitness function is established to convert the single response to multi-response. Genetic Algorithm (GA) is used to enhance the results of DFA and the regression model was developed to obtain the objective function of Genetic algorithm. Smaller-the-best criteria were used for 'Increase in Temperature' and 'Increase in Hardness' for obtaining favorable process parameters. The best optimal parametric combination is obtained by using the GA-DFA hybrid approach is at $2.5 \mathrm{~mm}$ (working gap), $20 \mathrm{gm}$ (abrasive weight), and $2.0 \mathrm{~A}$ (Current) and $300 \mathrm{rpm}$ (rotational speed).
\end{abstract}

Keywords: Magnetic abrasive particles, Temperature, Hardness, Genetic algorithm, Desirability function analysis.

DOI: http://dx.doi.org/10.4314/ijest.v13i1.1S

Cite this article as:

Singh R.K., Gangwar S., Singh D.K., Ahmad S. 2021. Multi-objective optimization of magnetic abrasive finishing by desirability function with genetic algorithm, International Journal of Engineering, Science and Technology, Vol. 13, No. 1, pp. 1-9. doi: 10.4314/ijest.v13i1.1S

Received: December 1, 2019; Accepted: February 5, 2021; Final acceptance in revised form: March 31, 2021

This paper was earlier presented at the International Conference on Energy, Environment \& Material Sciences (ICE2M), 1-3 December 2019 and substantially improved for this Special Issue. Guest Editor: Dr. Sri Niwas Singh, Professor (HAG), Department of Electrical Engineering, Indian Institute of Technology Kanpur, 208016 (U.P.) India, former Vice-Chancellor, Madan Mohan Malviya University of Technology Gorakhpur (April 2017 to July 2020).

\section{Introduction}

The magnetic abrasive finishing process was familiarized to enhance the surface texture of advanced matters such as superalloys, ceramics and composites (Fox et al., 1994). This process applies the magnetic flux to regulate the magnetic-abrasive brush (MAB), through its material removal from the desired surface take place. MAB is the composition of magnetic particles (iron particles) and abrasive particles (SiC). Finishing is accomplished when these magnetic abrasive particles (MAPs) are put into the machining gap sandwiched between the processed surface and magnetic tool (Singh et al., 2005). The magnetic flux assembles the MAPs in the form of MAB and its stiffness depends on the magnetic flux intensity in the machining gap. Super-finishing is 
accomplished by relative motion between the processed surface and MAB (Ahmad et al., 2017; Singh et al., 2004). This MAB acts as multi-point cutting head that remove the material in the form of micro-chips from the processed surface (Yamaguchi et al., 2012). During super-finishing a considerable quantity of heat is produced on machined surface due to "plastic distortion" and "frictional heat" (Mishra et al., 2014).

The produced heat affects the surface integrity of the machined surface. There have been many attempts made by researchers to predict the temperature and its effect on the target surface (Kumar and Yadav, 2009; Mulik et al., 2012). Surface hardness is other property that affects the surface-integrity of the machined surface (Hashimoto et al., 2016). In this finishing, temperature generation causes alteration of target surface hardness, and an increased hardness is beneficial for tribological application thus and a controlled operation is necessary (Levashov et al., 2011). It is impossible to avoid heat generation so in the process of minimizing the heat generation, benefits of hardness improvement have been exploited in this paper.

Bhagavatula and Komanduri (1996) explained that during super-finishing, the solid-phase reaction took place between workpiece and abrasive due to extreme pressure and temperature that is primarily produced by frictional heat during superfinishing. This phase reaction creates a chemical matter on the processed surface, altering its surface integrity. Further, Kumar and Yadav (2009) developed a finite element model to study the surface temperature effect on the processed surface. Inferences were made that temperature raised due to raise in MAB velocity \& magnetic flux. Further, Singh et al. performed an experimental analysis of temperature on the FMAB-workpiece boundary and took aluminum 6060 as a workpiece for performing experiments in MAF process. Major outcome was surface temperature clearly depends on abrasive weight, voltage and working gap (Mulik et al., 2012).

To show the effect of the MAF process on the surface hardness of the processed surface, M.naif explored the influence on the surface hardness of the brass plate, finished via MAF process ( M.naif et al., 2019). He performed a regression analysis to forecast the utmost substantial parameters affecting the response parameters. Hardness raised with raised in powder level and coil current and it reduced with a raise in rotational speed and working gap. Further, Ahmad et al. carry out research to examine the impact of abrasive size on the roughness of the finished surface (Ahmad et al., 2020). They employed the ANOVA to reveal the most influential process parameters to the response parameters. They also compared Taguchi and ANN-GA for best optimization for MAF process.

To examine the role of optimization in finishing process for the evaluation of their performance, various investigations were performed. The optimizations demonstrated improve in the capability of the manufacturing procedure, could very well implemented in industrial applications. Singh et al. combined the Simulated annealing with GRA to improve the surface texture of Aluminum 6060 workpiece finished via MAF. Their hybrid method had efficiently optimized the MAF performance (Kumar et al., 2020). Azhiri et al established a hybrid optimization method by merging "neuro-fuzzy" system with GRA to optimize the "surface roughness and cutting velocity" of Aluminium composite machined by WEDM. Their investigations were based on Taguchi's method and ANOVA revealed the most substantial process parameters (Bagherian Azhiri et al., 2014). Lately, Singh et al. had established a hybrid optimization technique by joining the Artificial neural network with Moth flame optimization. Their new methodology had successfully optimized the MAF process. they key findings were voltage, and the working gap should be kept at a minimum to achieve a better surface finish and hardness (Singh et al., 2019).

Ahmad et al. optimized five responses of the MAF utilizing the ANN-GA for multi-objective optimization. They used titanium to analyze the performance attributes between 5 parameters to 3 responses. Finally, their method positively optimized process parameters to enhance productivity of MAF (Ahmad et al., n.d.). Singh et al. applied DFA to optimize the responses of magnetic abrasive finishing. They used Aluminum 6060 that highly needed in the industries and importance of parameters were optimized by employing the PSO (Singh et al., 2020).

Pasandideh et al. studied that the simulation, generates requisite input data set from a simulated system with the desirability function analysis that can model the multi-response statistical data effectively, and the genetic algorithm effectively optimizes the model. This technique incorporates four strategies that di $\square$ er from one another in controlling the arbitrariness of the issue (Pasandideh and Niaki, 2006). In other studies, the authors have found a simultaneously optimizing multiple responses approach considers the ambiguity related to the fitted response surface model. The projected method has exceptionality because of its capability of considering all values intermediate to the chosen confidence interval rather than choosing only predicted values corresponding to a particular response and then defines the sturdiness measure for the conventional desirability function using the pessimistic case. A hybrid GA-DFA is developed to find the robust optima (He et al., 2012).

Table 1. Chemical composition of EN-31

\begin{tabular}{|l|l|l|l|l|l|l|}
\hline Elements & $\mathrm{C}$ & $\mathrm{Mn}$ & $\mathrm{S}$ & $\mathrm{P}$ & $\mathrm{Cr}$ & Fe \\
\hline Percentage & 1.10 & 9.02 & 0.04 & 0.04 & 1.3 & Rest \\
\hline
\end{tabular}

Literature review enlightens that so far, few multi-objective optimizations of response had been performed for the MAF process. The present study focuses on the Desirability function analysis of EN-31 finished through the MAF process and to enhance the results of DFA, a metaheuristic-based Genetic algorithm is used. In this research work, a hybrid optimization of the MAF process is developed by combining DFA with GA i.e., DFA-GA approach. This method is used to optimize the response measures of the 
EN-31 surface when finished using the MAF process. 'Increase in temperature' and 'Increase in Hardness' are selected as a response for optimization and their influence has been minimizing to get the best desired performance.

The novelty of this paper is to exploit the benefits of hardness improvement in the process of minimizing heat generation. The desirability function is used to model the multi-response data, the simulation method produces the essential input data from a simulated system, and lastly, metaheuristic genetic algorithm has been implemented for multi-objective optimization of the model.

\section{Experimentation of EN-31 by Magnetic abrasive finishing}

The surface temperature experiments were done to acquire the 'Increase in temperature' of the target surface of EN-31. To register any alteration in hardness on the workpiece surface, pre-finishing and post-finishing hardness testing were done. The major responses that were selected for multi-objective optimization were 'Increase in Temperature' and 'Increase in Hardness' of EN-31 workpiece. The experiments were conducted on the EN-31 workpiece of dimension 100x100x10 $\mathrm{mm}^{3}$ and the chemical composition was obtained by conducting the EDS test that shown in table 1 . The selected process parameters are shown in table 2. The experimentation range of process parameters was selected on MAF set-up design considerations and constrains.

Table 2. Selected process parameters range

\begin{tabular}{|c|c|c|c|c|c|c|}
\hline \multirow[t]{2}{*}{ S. No } & \multicolumn{2}{|c|}{ Process parameters } & \multicolumn{3}{|c|}{ Taguchi $\mathrm{L}_{9} \mathrm{OA}$} & \multirow[t]{2}{*}{ Units } \\
\hline & & & Level 1 & Level 2 & Level 3 & \\
\hline $\mathbf{A}$ & $\mathrm{P} 1$ & Working gap & 1.0 & 1.5 & 2.0 & $\mathrm{~mm}$ \\
\hline B & $\mathrm{P} 2$ & Abrasive weight & 20 & 25 & 30 & $\mathrm{~g}$ \\
\hline $\mathbf{C}$ & P3 & Current & 3 & 4.5 & 6 & A \\
\hline D & P4 & Rotational speed & 100 & 200 & 300 & $\mathrm{rpm}$ \\
\hline
\end{tabular}

Initially, a Surface hardness test was done employing Vicker's test before the super-finishing of EN-31. Hardness was measured by selecting five different positions on samples before super-finishing via MAF process. $30 \mathrm{kgf}$ load was employed to extract the pre-finishing hardness of EN-31. An average value was taken to determine the pre-hardness. The average Vickers hardness of 9 test samples was found in-between '131- 136' HV. After the super-finishing of EN-31, for the measurement hardness again Vickers test was performed for 9 test samples at five different locations.

Then, Surface temperature experiments of EN-31 were conducted using the MAF process shown in figure (1) to access the Increase in temperature. At first pilot experiments were performed to study the preliminary behavior of the MAF process. While performing pilot surface temperature experiments, it was seen that an increase in surface temperature had become constant approximately after 20 minutes and main surface temperature experiments were carried out for 20 minutes only. After that, Taguchi L9 orthogonal array was applied for systematic experiments. A total of nine experiments was conducted using different processing conditions shown in table 3. The experimental results showed the maximum surface temperature in EN-31 was found to be $41^{\circ} \mathrm{C}$ with respect to the ambient temperature of $23{ }^{\circ} \mathrm{C}$. Table 4 shows the 'Increase in Temperature' $(\Delta \mathrm{T})$ during the finishing of EN-31 for all experiments.

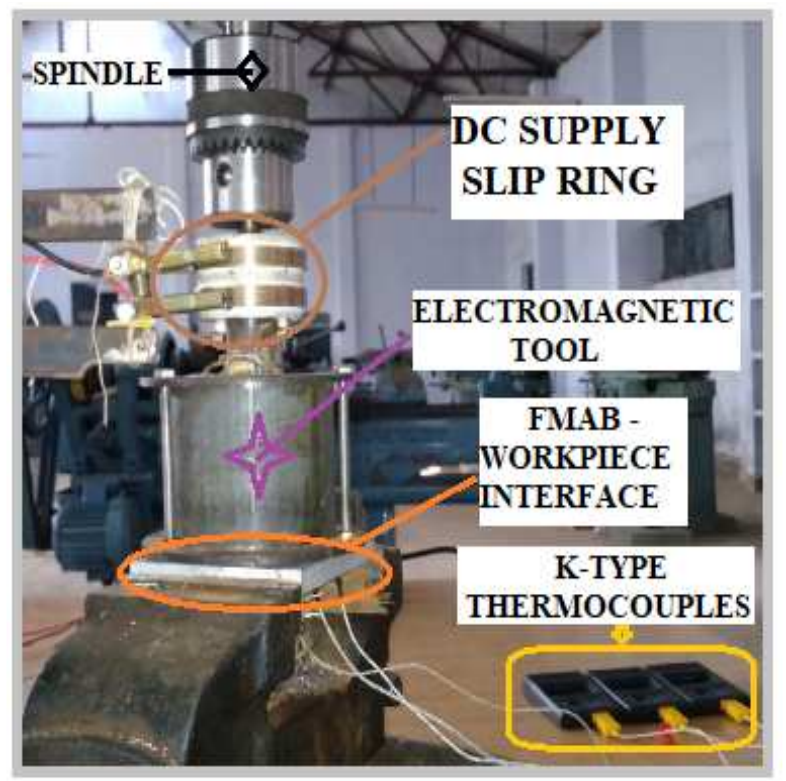

Figure. 1. Magnetic abrasive finishing experimental set-up 
To examine any changes in hardness on the finished surface after conducting surface temperature experiment of EN-31, Vickers's hardness test was performed. Again, $30 \mathrm{kgf}$ load was applied to find post super-finishing hardness of EN-31 at the different location. It was found that average final hardness of EN-31 is between '135.5-142.6' HV. The post super-finishing hardness was Increased by '4-7' HV approx. of all the nine test samples. Table 4 shows the 'Increase in hardness' $(\Delta \mathrm{H})$ of prefinishing and post-finishing of EN-31. Experimental results concluded that, there was Increase in both temperature and hardness during the finishing of EN-31 through MAF process that shown in table 4 . Maximum Increase in temperature of $18^{\circ} \mathrm{C}$ was register for processing condition 3 and maximum alteration of hardness of $6.6 \mathrm{HV}$ was achieved for processing condition 3 . For examining the combined effect of 'Increase in Temperature' and 'Increase in Hardness' on finishing of EN-31 using MAF process, desirability function coupled with genetic algorithm is used for multi-objective optimization of process parameters.

Table 3. Surface temperature experimental results

\begin{tabular}{|c|c|c|c|c|c|c|}
\hline TRIALS & $\mathbf{P}_{\mathbf{1}}$ & $\mathbf{P}_{\mathbf{2}}$ & $\mathbf{P}_{\mathbf{3}}$ & $\mathbf{P}_{\mathbf{4}}$ & $\mathbf{\Delta} \mathbf{T}$ & $\mathbf{\Delta} \mathbf{H}$ \\
\hline $\mathbf{1}$ & 1.0 & 20 & 3.0 & 100 & 07 & 4.5 \\
\hline $\mathbf{2}$ & 1.0 & 25 & 4.5 & 200 & 12 & 5.6 \\
\hline $\mathbf{3}$ & 1.0 & 30 & 6.0 & 300 & 18 & 6.6 \\
\hline $\mathbf{4}$ & 1.5 & 20 & 4.5 & 300 & 09 & 5.1 \\
\hline $\mathbf{5}$ & 1.5 & 25 & 6.0 & 100 & 14 & 5.6 \\
\hline $\mathbf{6}$ & 1.5 & 30 & 3.0 & 200 & 11 & 5.4 \\
\hline $\mathbf{7}$ & 2.0 & 20 & 6.0 & 200 & 10 & 5.0 \\
\hline $\mathbf{8}$ & 2.0 & 25 & 3.0 & 300 & 07 & 4.3 \\
\hline $\mathbf{9}$ & 2.0 & 30 & 4.5 & 100 & 08 & 6.0 \\
\hline
\end{tabular}

\section{Implementation of Desirability function}

Derringer and Suich presented the DFA to translate multi-response process into a single response in the form of desirability index $\left(\mathrm{d}_{\mathrm{i}}\right)$. They proposed three basic criteria for desirability functions. These functions were "Nominal-the-best", "Smaller-thebest", and "Larger-the-best". Where the desirability function y essentially lives amongst 0 to 1.

$$
d_{i}=\left\{\begin{array}{cc}
1, & \hat{y} \leq y \text { min } \\
\left(\frac{\hat{y}-y_{\max }}{y \min -y_{\max }}\right), \quad y \min \leq \hat{y} \leq y_{\max }, & r \geq 0 \\
0, & \hat{y} \geq y \text { max }
\end{array}\right.
$$

Step 1: The "single desirability index" is computed for "Increase in Temperature" and "Increase in Hardness" obtained after the experimentations of MAF process, provide in table 3. Aim is to minimalize both the chosen responses, therefore smaller-the-best desirability function is applied obtain desired characteristics. Single desirability index of "Increase in Temperature" and "Increase in Hardness" are listed in the table 4, which is computed by equation (1).

Table 4. Single desirability of experimental responses

\begin{tabular}{|c|c|c|c|c|}
\hline TRIALS & $\boldsymbol{\Delta} \mathbf{T}$ & $\mathbf{\Delta H}$ & $\mathbf{d}_{\mathbf{G}}$ & $\mathbf{D F F}$ \\
\hline $\mathbf{1}$ & 1 & 0.913 & 0.955 & 0.511 \\
\hline $\mathbf{2}$ & 0.545 & 0.434 & 0.486 & 0.672 \\
\hline $\mathbf{3}$ & 0 & 0 & 0 & 1 \\
\hline $\mathbf{4}$ & 0.818 & 0.652 & 0.730 & 0.577 \\
\hline $\mathbf{5}$ & 0.363 & 0.434 & 0.397 & 0.715 \\
\hline $\mathbf{6}$ & 0.636 & 0.521 & 0.576 & 0.634 \\
\hline $\mathbf{7}$ & 0.727 & 0.695 & 0.711 & 0.584 \\
\hline $\mathbf{8}$ & 1 & 1 & 1 & 0.5 \\
\hline $\mathbf{9}$ & 0.909 & 0.260 & 0.486 & 0.672 \\
\hline
\end{tabular}

Step 2: Then "composite desirability" $\left(\mathrm{d}_{\mathrm{G}}\right)$ which a single variable is computed by merging the "single desirability index" of both the responses via following equation-

$$
d_{G}=\sqrt[w]{\left(d_{1}{ }^{w 1} * d_{2}{ }^{w 2} \ldots \ldots . . * d_{i}{ }^{w i}\right)}
$$

here di is the "single desirability index", $\mathrm{w}_{\mathrm{i}}$ is the weight of the "single desirability index" of the responses and w is the summation of the single weights. The "composite desirability value" is calculated by merging the "single desirability index" of "Increase in Temperature" and "Increase in Hardness" employing the equation (2) is listed in table 4. Weight is a vital feature of "composite 
desirability" and it can be between 1 to 5, according to the significance of the responses. Here, similar weight is given to both the responses and weight of 5 is assigned to them.

Step 3: Lastly, the "desirability fitness function" (DFF) is estimated to get the optimal response. This DFF is calculated applying the following equation-

$$
\mathrm{DFF}=\frac{1}{1+d_{G}}
$$

DFF is determined using equation (3) and anticipated optimal level of the responses has selected on the DFF. Lower the DFF value, improved the surface finishing result. The minimum DFF is obtained for experiment 8 and maximum for experiment 3 as shown in table 4. DFF for experiment 8 is obtain the optimal level for finishing result, along with the optimal value based on the least DFF that are A3B2C1D4. Further, DFF are applied with meta-heuristic Genetic algorithm (GA) to acquire best parametric sets to further enhance the finishing capability of MAF process.

\subsection{Regression Analysis for Desirability Fitness Function}

An empirical regression model between desirability fitness function of responses with respect to the process parameters i.e., "working gap, abrasive weight, current and rotational speed" is developed. Montgomery (2000) had explained the implications and advantages of regression model and empirical model for this study is developed on MINITAB 18 statistical software. The regression results are listed in the table 5 and adequacy of DFF model is established by T-test which confirms the validity of developed DFF model. This model is competent as T-value is substantially small for all the coefficients that lie between -0.336 to 0.238 . DFF regression model equation is provided below.

$$
\mathrm{DFF}=-0.049-0.1423 \mathrm{P} 1+0.02111 \mathrm{P} 2+0.07267 \mathrm{P} 3+0.000298 \mathrm{P} 4
$$

Analysis of variance (ANOVA) is sophisticated method in determining the significance of process parameters with respect to desirability fitness function. ANOVA has forecasted the percentage contribution of the parameters to the DFF. Table 5 shows that maximum percentage contribution is done by current which is $39.78 \%$. followed by abrasive weight $37.30 \%$, working gap with $16.96 \%$.

Table 5. ANOVA forecast

\begin{tabular}{|c|c|c|c|c|c|}
\hline Source & DF & Seq SS & Contribution & Adj SS & P-Value \\
\hline Regression & 4 & 0.173 & $96.99 \%$ & 0.1738 & 0.003 \\
\hline P1 & 1 & 0.030 & $16.96 \%$ & 0.0303 & 0.009 \\
\hline P2 & 1 & 0.066 & $37.30 \%$ & 0.0668 & 0.002 \\
\hline P3 & 1 & 0.071 & $39.78 \%$ & 0.0712 & 0.002 \\
\hline P4 & 1 & 0.005 & $2.96 \%$ & 0.0053 & 0.118 \\
\hline Error & 4 & 0.005 & $3.01 \%$ & 0.0053 & \\
\hline Total & 8 & 0.179 & $100.00 \%$ & & \\
\hline
\end{tabular}

\subsection{Implementation of Genetic Algorithm}

Genetic algorithm (GA) is applied to build a metaheuristic GA-DFF forecasting model, for better forecasting of the best setting of finishing parameters. Genetic algorithm (GA) comes in class of meta-heuristic evolutionary algorithm. It is inspired by the logical revelation of natural selection. This method is used to generate impeccable solutions in field of optimization and pattern search problem rely on biological operatives such as selection, mutation and cross over. Genetic Algorithm optimization is implemented to process the results of desirability fitness function to improve the result of multi-response optimization. GA is employed using Optimization toolbox in "MATLAB". Objective function formulated applying regression equation, that is again utilized to optimize the DFF response. In order to achieve the best parametric optimal level for desirable surface finish of EN-31 metaheuristic approach is further applied.

Table 6. Comparison between DFF and GA-DFF

\begin{tabular}{|c|c|c|c|c|c|c|c|}
\hline TRIALS & $\mathbf{P}_{\mathbf{1}}$ & $\mathbf{P}_{\mathbf{2}}$ & $\mathbf{P}_{\mathbf{3}}$ & $\mathbf{P}_{\mathbf{4}}$ & $\mathbf{D F F}$ & GA-DFF & \%ERROR \\
\hline $\mathbf{1}$ & 1.0 & 20 & 3.0 & 100 & 0.511 & 0.520 & 1.877 \\
\hline $\mathbf{2}$ & 1.0 & 25 & 4.5 & 200 & 0.672 & 0.695 & 3.479 \\
\hline $\mathbf{3}$ & 1.0 & 30 & 6.0 & 300 & 1.000 & 0.967 & -3.260 \\
\hline $\mathbf{4}$ & 1.5 & 20 & 4.5 & 300 & 0.577 & 0.577 & -0.034 \\
\hline $\mathbf{5}$ & 1.5 & 25 & 6.0 & 100 & 0.715 & 0.731 & 2.180 \\
\hline $\mathbf{6}$ & 1.5 & 30 & 3.0 & 200 & 0.634 & 0.648 & 2.206 \\
\hline $\mathbf{7}$ & 2.0 & 20 & 6.0 & 200 & 0.584 & 0.584 & 0.034 \\
\hline $\mathbf{8}$ & 2.0 & 25 & 3.0 & 300 & 0.500 & 0.495 & -0.960 \\
\hline $\mathbf{9}$ & 2.0 & 30 & 4.5 & 100 & 0.672 & 0.656 & -2.379 \\
\hline
\end{tabular}


GA is employed by utilizing objective function that is based on the DFF regression equation. This objective function is to discover the global minima result of DFF. Objective function is fed in optimization toolbox. It begins with, assigning upper-lower bound of the objective function, selected from the different finishing settings listed in table 6. 500 population size and Double vector population type along with feasible populational creation function are taken. Then "rank scaling function, stochastic uniform selection function, adaptive feasible mutation function" is decided. At last heuristic crossover and forward migration are opted.

\subsection{Genetic algorithm - Desirability function analysis}

The GA-DFA model, simulated results with an $\%$ error amongst $-3.2600 \%$ to $+3.4795 \%$, which is a satisfactory forecast rate. GADFF global optimal result for all nine experiments was found, i.e., listed in table 6. GA-DFF is lowest for experiment-8 i.e., 0.4952, shown in figure (2) depicting the best optimal condition for "Increase in Temperature" and "Increase in Hardness" for finding desirable capability for finishing of EN-31 via MAF process. Maximum GA-DFF value is found at experiment-3 i.e., 0.9674 , that is the poorest optimal state for finishing. Table 6 displays the error amongst the DFF and GA-DFF for nine trials.

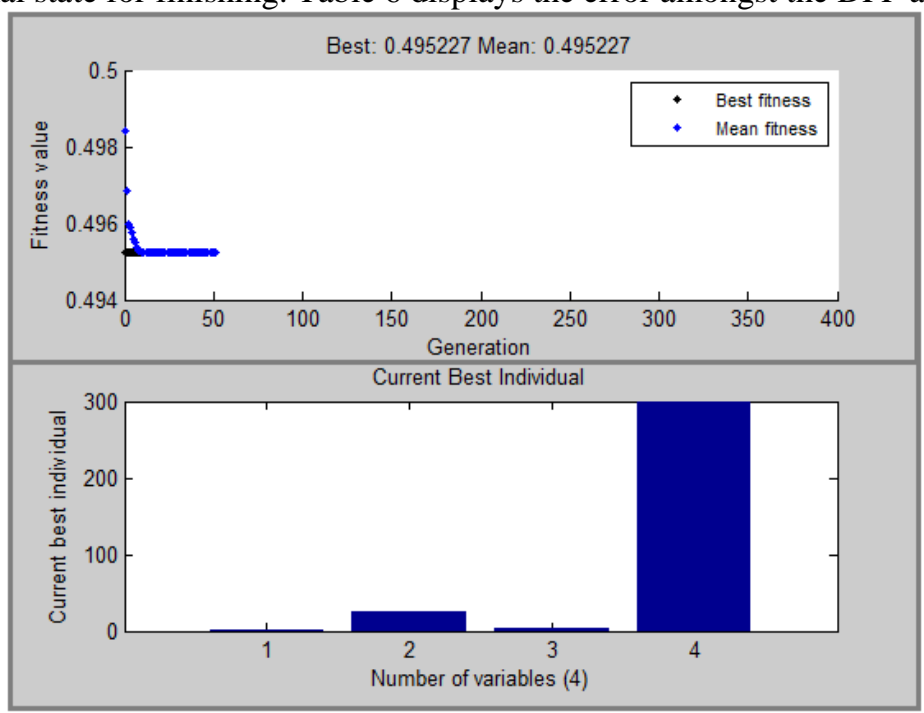

Figure. 2. Best fitness value of GA- DFA for experiment 8

\subsection{GA-DFF for process parameters}

The best parametric levels of Taguchi-based Desirability function (A3B2C1D4) were predicted via meta-heuristic genetic algorithm. The projected output of GA-DFA, post simulation was 0.4952. To acquire the best parameter level using GA module, one parameter was changed into different level, while other parameters were fixed. The parameter A (P1, working gap) level was changed from " $1.5 \mathrm{~mm}$ to $2.5 \mathrm{~mm}$ ", while others were fixed i.e., B2C1D4 level. For parameter B (P2, abrasive weight), the level was changed from " $20 \mathrm{~g}$ to $30 \mathrm{~g}$ ", while others were fixed at A3C1D4 level. Last, parameter C (P3, current) level was changed from 2A to $4 \mathrm{~A}$, while others were fixed at A3B1D4 level. The forecasted results for parameters A, B and C with respect to DFF are displays in Figure 3 (a-c) correspondingly.

Table 7. Comparative results

\begin{tabular}{|c|c|c|c|c|c|c|}
\hline \multirow{2}{*}{ Method } & \multicolumn{4}{|c|}{ Optimal parametric setting } & DFF & \% \\
\cline { 2 - 6 } & $\mathbf{P}_{\mathbf{1}}$ & $\mathbf{P}_{\mathbf{2}}$ & $\mathbf{P}_{\mathbf{3}}$ & $\mathbf{P}_{\mathbf{4}}$ & & $\begin{array}{c}\text { \% } \\
\text { IN DFF }\end{array}$ \\
\hline Taguchi-GRA & $2.0 \mathrm{~mm}$ & $25 \mathrm{~g}$ & $3 \mathrm{~A}$ & $300 \mathrm{rpm}$ & 0.5000 & \\
\hline $\begin{array}{c}\text { Taguchi-GA-DFF } \\
\text { (predicted) }\end{array}$ & $2.0 \mathrm{~mm}$ & $25 \mathrm{~g}$ & $3 \mathrm{~A}$ & $300 \mathrm{rpm}$ & 0.4952 & $0.96 \%$ \\
\hline $\begin{array}{c}\text { Taguchi-GA-DFF } \\
\text { (optimized) }\end{array}$ & $2.5 \mathrm{~mm}$ & $20 \mathrm{~g}$ & $2 \mathrm{~A}$ & $300 \mathrm{rpm}$ & 0.4155 & $16.93 \%$ \\
\hline
\end{tabular}

\section{Validation tests}

The confirmation test was done to establish the optimal setting projected by $\mathrm{L}_{9}$ OA based GA-DFF with the experimental results. Simulation built on the forecasted parameters through Taguchi was performed. Final forecasted GA-DFF value was 0.4155. Table 7 displays the experimental results that were found by utilizing the optimal parameters forecasted by $\mathrm{L}_{9} \mathrm{OA}$ of Taguchi-GRA model and $\mathrm{L}_{9} \mathrm{OA}$ of Taguchi-based GA-DFF model. The forecasted DFF of parameters via $\mathrm{L}_{9} \mathrm{OA}$ of Taguchi-based GA-DFF model has been enhanced by $16.93 \%$ which (Table 7) shows the agreeably performance of optimization model. Hence, it 
is found that "Increase in Temperature" and "Increase in Hardness" can be concurrently optimized using a $\mathrm{L}_{9} \mathrm{OA}$ of Taguchi-based GA-DFA model. Furthermore, the vigorous optimization can be implemented through the assistance of genetic algorithm model, forecasting the values beyond the defined parametric level.
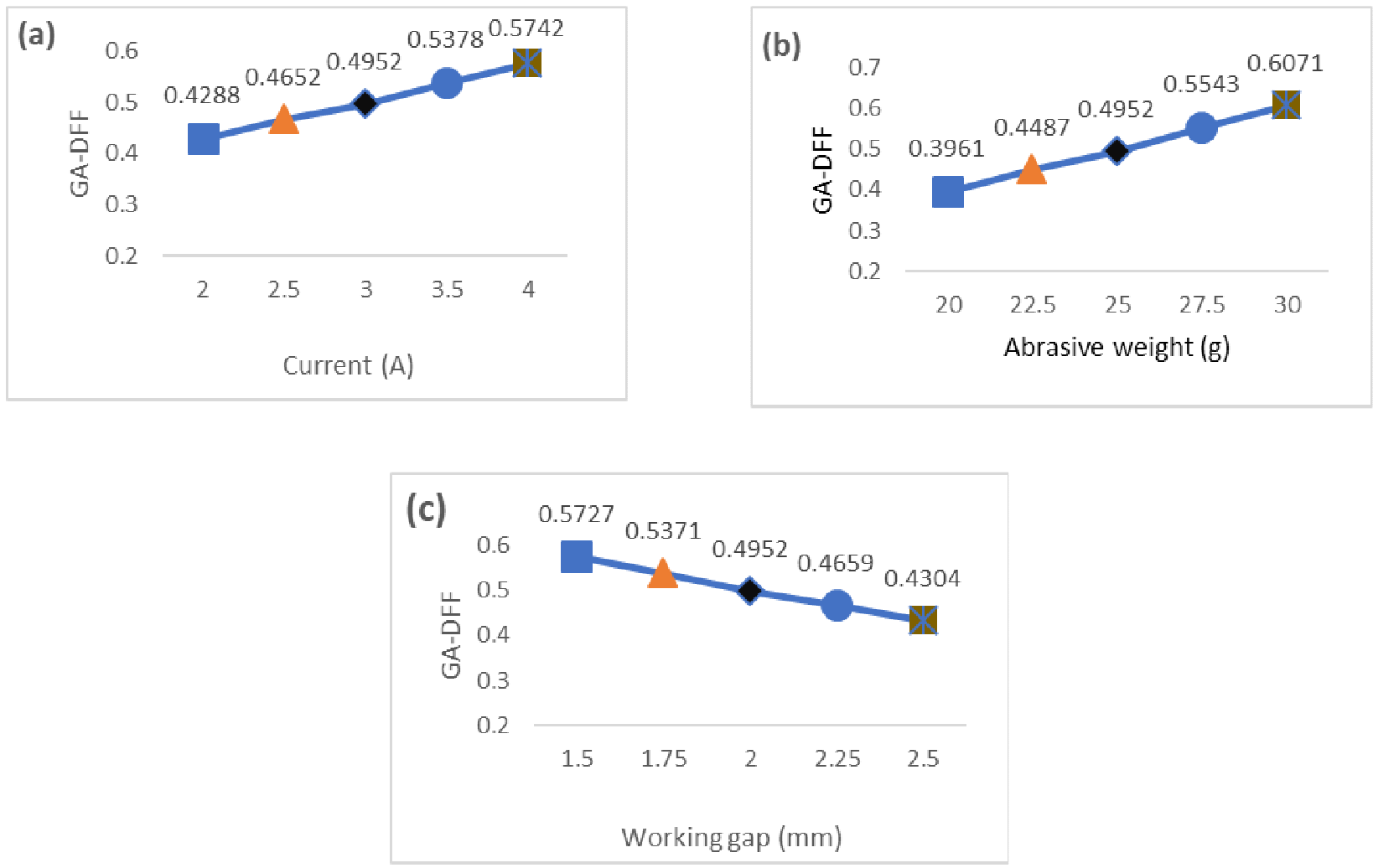

Figure.3. Simulation Results for Multiple Levels of (a) current, (b) abrasive weight, (c) working gap

\section{Conclusion}

GA-DFA Multi-objective optimization for "Increase in Temperature" and "Increase in Hardness" has successfully enhanced the performance of the MAF process. "Increase in Temperature" and "Increase in Hardness" are the responses that impact the surface quality of finished EN-31. Any modification in desired surface texture would propagate failures in manufactured parts with EN-31 and this failure would terminate the running machinery. To diminish the effects of "Increase in Temperature" and "Increase in Hardness" of finished surface in EN-31, DFA is done to study the combine role of responses. DFA and Genetic algorithm are combined to form a hybrid optimization approach i.e., GA-DFA. The advantage of GA-DFA technique over meta-heuristic approaches, that it can be applied for continuous quality assessment and on-line quality directive for manufacturing product. Hence following conclusions are drawn,

- DFA is applied to reduce the influence of "Increase in Temperature" and "Increase in Hardness" on the finished surface of EN-31 using MAF process. DFA is coupled with genetic algorithm to predict the best optimal level to produce the best surface quality in EN-31.

- Regression analysis is done to establish relationship between process parameters and Desirability fitness function of "Increase in Temperature" and "Increase in Hardness". The most significant process parameters are current and abrasive weight.

- ANOVA provided the percentage contribution of each parameters in respect with DFF. "Current" contributed most with $39.78 \%$, trailed by "abrasive weight" with $37.30 \%$ and "working gap" with $16.96 \%$. The least contribution is done by Rotational speed with $2.96 \%$.

- Genetic algorithm is employed to enhance the DFA results, as DFF forecasted the optimal parametric setting. At trial 8, GA forecasted lowest GA-DFF i.e., 0.4952 with A3B2C1D4 parametric setting and this sequence of parameters will produce best surface finish on EN-31. 
- The simulation using meta-heuristic GA-DFA had forecasted best parametric level i.e., "working gap" (2.5mm), "abrasive weight" (20 g) and "current" (2), produced the uppermost GRG to amplify the capability of MAF process in order to finish EN-31 surface.

- Predicted DFF of parameters via $\mathrm{L}_{9} \mathrm{OA}$ of Taguchi-based GA-DFA is enhanced by $16.93 \%$, that displays a acceptable performance of the above-stated optimization method.

$\begin{array}{ll}\text { Nomenclature } & \\ \text { DFA } & \text { Desirability function analysis } \\ \text { GA } & \text { Genetic Algorithm } \\ \text { MAB } & \text { magnetic-abrasive brush } \\ d_{G} & \text { composite desirability } \\ \text { DFF } & \text { desirability fitness function } \\ \text { ANOVA } & \text { Analysis of variance } \\ \text { L }_{9} \mathrm{OA} & \text { L } 9 \text { Orthogonal array }\end{array}$

\section{Acknowledgement}

The authors are very grateful to the TEQIP-II, the "Council of Scientific and Industrial Research (CSIR) - Government of India," for financial support in the form of SRF.

\section{References}

Ahmad, S., Gangwar, S., Yadav, P.C., Singh, D.K., 2017. Optimization of process parameters affecting surface roughness in magnetic abrasive finishing process. Materials and Manufacturing Processes, Vol. 32, pp. 1723-1729. https://doi.org/10.1080/10426914.2017.1279307

Ahmad, S., Singari, R.M., Mishra, R.S., 2020. Modelling and optimisation of magnetic abrasive finishing process based on a nonorthogonal array with ANN-GA approach. Transactions of the IMF, Vol. 98, pp. 186-198. https://doi.org/10.1080/00202967.2020.1776966

Ahmad, S., Singari, R.M., Mishra, R.S., n.d. Tri-objective constrained optimization of pulsating DC sourced magnetic abrasive finishing process parameters using artificial neural network and genetic algorithm. Materials and Manufacturing Processes. https://doi.org/Manuscript DOI: 10.1080/10426914.2020.1866196

Bagherian Azhiri, R., Teimouri, R., Ghasemi Baboly, M., Leseman, Z., 2014. Application of Taguchi, ANFIS and grey relational analysis for studying, modeling and optimization of wire EDM process while using gaseous media. International Journal of Advanced Manufacturing Technology, Vol. 71, pp. 279-295. https://doi.org/10.1007/s00170-013-5467-y

Bhagavatula, S.R., Komanduri, R., 1996. On chemomechanical polishing of $\mathrm{Si}_{3} \mathrm{~N}_{4}$ with $\mathrm{Cr}_{2} \mathrm{O}_{3}$. Philosophical Magazine A, Vol. 74, pp. 1003-1017. https://doi.org/10.1080/01418619608242173

Fox, M., Agrawal, K., Shinmura, T., Komanduri, R., 1994. Magnetic abrasive finishing of rollers. CIRP Annals, Vol. 43, pp. 181184. https://doi.org/10.1016/S0007-8506(07)62191-X

Hashimoto, F., Yamaguchi, H., Krajnik, P., Wegener, K., Chaudhari, R., Hoffmeister, H.-W., Kuster, F., 2016. Abrasive finefinishing technology. CIRP Annals, Vol. 65, pp. 597-620. https://doi.org/10.1016/j.cirp.2016.06.003

He, Z., Zhu, P.-F., Park, S.-H., 2012. A robust desirability function method for multi-response surface optimization considering model uncertainty. European Journal of Operational Research, Vol. 221, pp. 241-247. https://doi.org/10.1016/j.ejor.2012.03.009

Kumar, G., Yadav, V., 2009. Temperature distribution in the workpiece due to plane magnetic abrasive finishing using FEM. International Journal of Advanced Manufacturing Technology, Vol. 41, pp. 1051-1058. https://doi.org/10.1007/s00170-008$1557-7$

Kumar, S., Gangwar, S., Singh, D.K., 2020. Exploration of GRA based multiobjective optimization of magnetic abrasive finishing process using simulated annealing. FME Transactions, Vol. 48, pp. 195-203. https://doi.org/10.5937/fmet2001195R

Levashov, E.A., Petrzhik, M.I., Tyurina, M.Ya., Kiryukhantsev-Korneev, F.V., Tsygankov, P.A., Rogachev, A.S., 2011. Multilayer nanostructured heat-generating coatings. Preparation and certification of mechanical and tribological properties. Metallurgist, Vol. 54, pp. 623-634. https://doi.org/10.1007/s11015-011-9350-5

Mishra, V., Goel, H., Mulik, R.S., Pandey, P.M., 2014. Determining work-brush interface temperature in magnetic abrasive finishing process. Journal of Manufacturing Processes, Vol. 16, pp. 248-256. https://doi.org/10.1016/j.jmapro.2013.10.004

Mulik, R.S., Srivastava, V., Pandey, P.M., 2012. Experimental investigations and modeling of temperature in the work-brush interface during ultrasonic assisted magnetic abrasive finishing process. Materials and Manufacturing Processes, Vol. 27, pp. 1-9. https://doi.org/10.1080/10426914.2010.515647 
Nazar, M. 2012. Study on the parameter optimization in magnetic abrasive polishing for brass Cuzn33 plate using taguchi method. Iraqi Journal for Mechanical and Materials Engineering, Vol. 12, pp. 596-615.

Pasandideh, S.H.R., Niaki, S.T.A., 2006. Multi-response simulation optimization using genetic algorithm within desirability function framework. Applied Mathematics and Computation, Vol..175, pp. 366-382. https://doi.org/10.1016/j.amc.2005.07.023

Singh, D.K., Jain, V.K., Raghuram, V., 2004. Parametric study of magnetic abrasive finishing process. Journal of Materials Processing Technology, Vol. 149, pp. 22-29. https://doi.org/10.1016/j.jmatprotec.2003.10.030

Singh, D.K., Jain, V.K., Raghuram, V., Komanduri, R., 2005. Analysis of surface texture generated by a flexible magnetic abrasive brush. Wear, Vol. 259, pp. 1254-1261. https://doi.org/10.1016/j.wear.2005.02.030

Singh, R.K., Gangwar, S., Singh, D.K., 2020. Exploration of desirability function analysis-based particle swarm optimization for magnetic abrasive finishing of mild steel. Journal of Advanced Manufacturing Systems, Vol. 19, pp. 607-627. https://doi.org/10.1142/S0219686720500298

Singh, R.K., Gangwar, S., Singh, D.K., Pathak, V.K., 2019. A novel hybridization of artificial neural network and moth-flame optimization (ANN-MFO) for multi-objective optimization in magnetic abrasive finishing of aluminium 6060. Journal of the Brazilian Society of Mechanical Sciences and Engineering, Vol. 41, 270. https://doi.org/10.1007/s40430-019-1778-8

Yamaguchi, H., Srivastava, A.K., Tan, M.A., Riveros, R.E., Hashimoto, F., 2012. Magnetic abrasive finishing of cutting tools for machining of titanium alloys. CIRP Annals, Vol. 61, pp. 311-314. https://doi.org/10.1016/j.cirp.2012.03.066

\section{Biographical notes}

Dr. Rajneesh Kumar Singh is working as an Assistant professor in Mechanical Engineering Department at Meerut Institute of Engineering and Technology, Meerut, Uttar Pradesh (India) since July 2020. He received his Ph.D. (Advanced Manufacturing Processes) from Madan Mohan Malaviya University of Technology, Gorakhpur, Uttar Pradesh (India). After graduation in Mechanical Engineering from Shri Ramswaroop College of Engineering and Management, Lucknow, Uttar Pradesh INDIA, he joined MMMEC Gorakhpur, Uttar Pradesh for her Post graduation in Mechanical Engineering with specialization of CIM. He has published more than 10 papers in peer reviewed Journals and International/ national conferences. He has authored a book chapter in Wiley Scrivener Journal. His area of interest is, Manufacturing Science, Advance Manufacturing, Computer Aided Manufacturing, Finite Element Method and Optimization.

Dr. Swati Gangwar is working as an Assistant Professor in Department of Mechanical Engineering at Madan Mohan Malaviya University of Technology, Gorakhpur, Uttar Pradesh (India) since January 2015. After graduation in Mechanical Engineering from Shri Ram Murti Smarak College of Engineering and Technology, Bareilly, Uttar Pradesh INDIA, she joined NIT Hamirpur, Himachal Pradesh for her Post graduation in Mechanical Engineering with specialization of CAD/CAM. After that she had obtained Degree of Philosophy of Doctorate from MNIT Jaipur, Rajasthan in 2016. She has published more than 80 papers in peer reviewed Journals and International/ national conferences within very short span of her carrier. She has authored a book chapter in Wiley Scrivener Journal and 5 book chapter in national and international conference. She has filed a Patent with patent no.1319/DEL/2015 A. Her areas of interest are Micro/Nano Composite, Bio-composites material, Tribology, Materials Characterizations, and Advance Manufacturing.

Prof D.K. Singh is working as a Professor of Mechanical Engineering, Madan Mohan Malaviya University of Technology, Gorakhpur (01, January 2008 to till date). Ex-Director, Rajkiya Engineering College (Formerly Manyawar Kanshi Ram Engineering College of Information Technology), Azamgarh (UP), Affiliated College of Dr.A.P.J. Abdul Kalam Technical University, Lucknow (Formerly U.P. Technical University) from 20 January 2015 to 19 January $2018 . \quad$ Head, Department of Mechanical Engineering, Madan Mohan Malaviya University of Technology (Formerly Madan Mohan Malaviya Engineering College), Gorakhpur (28thFebruary 2013 to 19th January 2015) and 31-12-2018 to till date. Assistant Professor of Mechanical Engineering, Madan Mohan Malaviya Engineering College, Gorakhpur (01, January 2000 to 31-12-2007). Assistant Professor, Mechanical Engineering Department, University of Garyounis, Libya, North Africa (October 2006 to July 2007). Lecturer of Mechanical Engineering, Madan Mohan Malaviya Engineering College, Gorakhpur (February 1988 to December 1999 ). Research Scholar, Mechanical Engineering Department, Indian Institute of Technology Kanpur (July 2000 to February 2005). Master Fellow, Mechanical \& Industrial Engineering Department, University of Roorkee, Roorkee, (July 1995 to February 1997). He has published more than 60 papers in peer reviewed Journals and International/ national conferences. He has authored and edited various a book chapter. He has filed a Patent on Indian Patent on "A Method for Magnetic Abrasive Finishing using a Pulsating Flexible Magnetic Abrasive Brush and a Magnetic Abrasive Finishing Device"Patent Application No. 1990/DEL/2005A filed Dated 27-07-2005 and Published on Patent Journal on 13-07-2007 International Classification: B24B 31/00. His areas of interest are Advanced Manufacturing Technology, Computer Controlled Manufacturing Processes, Machining Science, Computer Aided Process Planning (CAPP) of Manufacturing Processes, (Conventional/Unconventional), Application of Robust Design \& Design of Experiments in Engineering, Quality Engineering.

Shadab Ahmad is a research fellow at Mechanical Engineering Department, Delhi Technological University, Gorakhpur, India. He received his M Tech (Engineering) from MMM University of Tech. in Gorakhpur, India in 2015. He is actively interested in research in the fields of Advanced manufacturing processes, Magnetic assisted finishing, Composite material, Electro-Magneto-Thermo-Mechanics, Finite Element Analysis, Isogeometric Analysis, Optimization, Soft computing. He is also research coordinator at Center for advanced production and industrial engineering research (CAPIER), DTU Delhi. He worked as joint treasurer and editor of book of abstract in ICAPIE-2018. 